\title{
Longitudinal experience with Studer neobladders: Outcomes and complications
}

Ernest Pang Chan ${ }^{1}$; Shiva Madhwan Nair ${ }^{1}$; Khalil Hetou ${ }^{1,2}$; Emily Stephenson ${ }^{3}$; Nicholas E. Power'; Jonathan Izawa ${ }^{1}$; Joseph L.K. Chin ${ }^{1}$

${ }^{1}$ Division of Urology, Department of Surgery, Schulich School of Medicine \& Dentistry. London, ON, Canada; ${ }^{2}$ Department of Urology, Klinikum Bremen Mitte, Bremen, Germany; ${ }^{3}$ Department of Medicine, Schulich School of Medicine \& Dentistry, London, ON, Canada

Cite as: Chan EP, Nair SM, Hetou K, et al. Longitudinal experience with Studer neobladders: Outcomes and complications. Can Urol Assoc J 2021 January 4; Epub ahead of print. http://dx.doi.org/10.5489/cuaj.6893

Published online January 4, 2021

$* * *$

\section{Abstract}

Introduction: This study aims to assess the longer-term functional, anatomical, and metabolic outcomes of patients who underwent Studer neobladder (SNB) urinary diversion.

Methods: A retrospective review of patients who underwent SNB at a single center from 19952017 ( $n=116$ ) was performed. Demographics, comorbidities, pathological data, and longer-term functional, anatomical, and metabolic outcomes were collected from hospital records. The primary outcome was voiding function of patients at most recent followup. Secondary outcomes included postoperative complications, renal function, nephrolithiasis, infections, and metabolic outcomes.

Results: Excluding those with incomplete followup data, 72 patients with minimum followup of one year were included for analysis. Median followup was $70 \pm 11$ months, with $52.8 \%$ of patients having $\geq 5$ years of followup. Clean intermittent catheterization (CIC) was used by $22.2 \%$ of patient at most recent followup, which was mostly necessitated by bladder overdistension, deteriorating renal function, or recurrent urosepsis despite timed voiding. Patients experienced more daytime and nighttime urinary incontinence in the early postoperative setting that improved over time. Generally, renal function declined over time; poorer long-term renal function was predicted by hydronephrosis within one year $(\mathrm{p}=0.002)$.

Conclusions: Longer-term followup of SNB reveals significant but manageable complications. Gradual decline in renal function was common. Strict adherence to bladder emptying protocols (e.g., timed voiding or CIC) may reduce incidence of renal deterioration, metabolic disorders, and urinary dysfunction. Early onset $(<1$ year) of hydronephrosis may indicate a need for intervention to preserve long-term renal function. 


\section{Introduction}

Neobladder, as described by Studer, offers the advantages of superior cosmesis and potentially near-normal voiding function and continence for patients undergoing radical cystectomy. ${ }^{1}$ Creation of a Studer neobladder (SNB), however, may not be suitable for some patients due to metabolic, anatomic, oncologic, or demographic reasons. ${ }^{2,3}$ Neobladders using autologous bowel segments are also associated with a risk of long-term complications such as ureteral obstruction, urosepsis, metabolic derangements, urinary stone disease, fistula formation, and functional urinary impairment. ${ }^{4,5,6}$ Reports of SNB functional outcomes and management, renal function, and need for surgical correction of anatomical complications beyond five years have been limited. ${ }^{4,7-10}$

This study aims to assess the functional, anatomical, and metabolic outcomes of patients who have undergone Studer neobladder urinary diversion, with median followup beyond 5 years, at a Canadian tertiary care centre.

\section{Methods}

\section{Study design}

We conducted a retrospective study of patients who underwent SNB between January 1995 and May 2017 (N=116) performed by three surgeons. Standard surgical technique for SNB and postoperative care have been previously described by Studer et al. ${ }^{11}$ Extended pelvic lymphadenectomy was performed at the discretion of the surgeon.

Data collection was performed by retrospective review of electronic and paper charts. Patients who had less than one year of follow-up or incomplete follow-up were excluded. All patients were followed regularly in clinic with physical examination, basic laboratory assessment, postvoid residual, and surveillance imaging as per the AUA/ASCO/ASTRO/SUO guideline on follow-up of non-metastatic muscle-invasive bladder cancer. ${ }^{12}$ Follow-up data was collected until the most recent encounter with their operative surgeon at our centre. Institutional ethics aproval was received from Western University (REB\#: 109687)

\section{Outcome measures}

Basic demographic and tumor specific variables were obtained from review of the electronic record. Urinary outcomes, including daytime urinary incontinence (DUI), nighttime urinary incontinence (NUI), urinary frequency, nocturia, clean intermittent catheterization (CIC) and/or indwelling catheterization, and post-void residual (PVR), were collected based on surgeonreported outcomes derived from their most recent clinical documentation. DUI and NUI were defined as need for use of at least one incontinence pad during the daytime and nighttime, respectively. ${ }^{13-15}$ Use of prophylactic pads was not included. Continence was defined as no need 
for incontinence pads. Post-void residals were obtained by Bladder Scan BVI 3000 clinic ultrasonography (Verathon Inc, Bothell, WA).

Postoperative complications were documented, including the development of anastomotic leaks, fistulae, uretero-ileal stenosis, and neobladder neck contractures (i.e., fibrotic stenosis of the ileourethral anastomosis). Functional and metabolic outcomes were also documented, including recurrent urinary tract infections (UTI; defined as $\geq 3$ occurrences of symptomatic UTI per year requiring antibiotic treatment), urinary stone formation, electrolyte disorders (requiring supplementation), and vitamin B12 deficiencies (requiring supplementation).

For patients with less than 5 year follow-up, renal function was documented preoperatively (up to 6 months before surgery), at 6-12 months, and 1-5 years postoperatively (most recent). Postoperative renal function was documented at 10 years and 15 years for patients with longer follow-up ( $\geq 5$ years). Presence or absence of hydronephrosis was obtained from radiographic reports (computed tomorgraphy or ultrasound) and documented preoperatively, at 6-12 month follow-up, and most recent follow-up. Estimated glomerular filtration rate (eGFR) was calculated using the Modification of Diet in Renal Disease formula ${ }^{16}$, and categorized according to chronic kidney disease (CKD) stage.

\section{Data analysis}

Descriptive analysis of patient demographics, pathologic stage, postoperative complications, functional outcomes, and metabolic outcomes was performed. Patient outcomes were compared based on follow-up duration ( $<5$ vs. $\geq 5$ years $)$ and gender. Between group differences were calculated using Mann-Whitney U test for continuous variables and Fisher exact test for categorical variables based on nonparametric data. Univariate logistic regression was performed for predictors of renal function and functional outcomes. Statistical significance was set as $\mathrm{p}<0.05$. Statistical analysis was performed using SPSS (IBM SPSS Statistics for Windows, Version 21.0. Released 2012. Armonk, NY: IBM Corp.).

\section{Results}

Of the 116 patients who underwent radical cystectomy and SNB for bladder cancer, 72 met our inclusion criteria. Five patients $(4.3 \%)$ had early ( $<12$ months) postoperative follow-up with their local urologist and were excluded from anlaysis due to lack of long-term data. Patient demographics and tumor characteristics are outlined in Table 1. Surgeries were performed at a single institution by three urologic oncologists, accounting for $75 \%, 16.7 \%$, and $8.3 \%$ of our sample respectively.

Mean \pm SD patient age at surgery was $54.8 \pm 8.6$ years with a median \pm IQR preoperative Charlson comorbidity index (CCI) of $4 \pm 2$. A majority of patients had muscle-invasive disease $(\mathrm{n}=44 ; 61.1 \%)$. Median $\pm \mathrm{IQR}$ follow-up time was $70 \pm 11$ months. More than half $(\mathrm{n}=38$; $52.8 \%$ ) of our sample had $\geq 5$ years of follow-up. Baseline characteristics for comparison groups ( $<5$ vs. $\geq 5$ years, and male vs. female) were compared and similar in all categories except for 
histologic type, with a higher proportion of squamous cell carcinoma in females in this series $(p=0.007)$. Patients in the $\geq 5$ years subgroup had a longer duration of follow-up $(p<0.001)$.

\section{Functional outcomes}

Functional voiding outcomes are shown in Table 2 and Figure 1. All patients were advised and encouraged adherence to a timed voiding schedule. Despite this, approximately one-quarter of patients required catheterization ( 3 indwelling and $16 \mathrm{CIC}$ ).

Clean intermittent catheterization was initiated at our instutition when risk of SNB overdistension was identified through elevated PVR $(n=9)$, recurrent urinary retention $(n=3)$, deteriorating renal function $(n=1)$, increasing hydronephrosis $(n=1)$, or recurrent urosepsis $(n=2)$. Elevated PVR was defined as greater than $500 \mathrm{~mL}$ on bladder scan after best void (e.g., double voiding, Credé maneuver) as this was a threshold deemed acceptable to patients to initiate selfcatheterization. Patients who utilized CIC had mean PVR of $206.7 \mathrm{~mL}$ compared to those who did not (mean PVR: $78.1 \mathrm{~mL}$; $\mathrm{p}=0.024$ ). PVR was not associated with other functional voiding outcomes on linear regression. Need for CIC was not associated with age or follow-up duration on linear regression. Indications for permanent catheterization included incontinence, fistula, and patient preference.

The prevalence of NUI and DUI were similar between follow-up durations and patient sex (Table 2). Patients with longer follow-up reported a lower proportion of DUI (Figure 1). Pathological stage, age, and chemotherapy were not predictive of DUI or NUI.

\section{Renal function outcomes}

Mean eGFR prior to SNB was $88.27 \mathrm{~mL} / \mathrm{min} / 1.73 \mathrm{~m}^{2}$. At 6-12 months postoperative, mean eGFR decreased to $71.92 \mathrm{~mL} / \mathrm{min} / 1.73 \mathrm{~m}^{2}$. At $1-5$ years, 10 years, and 15 years follow-up, mean eGFR was $76.23 \mathrm{~mL} / \mathrm{min} / 1.73 \mathrm{~m}^{2}, 66.06 \mathrm{~mL} / \mathrm{min} / 1.73 \mathrm{~m}^{2}$, and $68.33 \mathrm{~mL} / \mathrm{min} / 1.73 \mathrm{~m}^{2}$, respectively. Mean eGFR change per year from preoperative eGFR was $-7.19 \mathrm{~mL} / \mathrm{min} / 1.73 \mathrm{~m}^{2}$ in the first year. Between postoperative years 1 to 5 , mean eGFR change per year was +0.862 $\mathrm{mL} / \mathrm{min} / 1.73 \mathrm{~m}^{2}$. Between years $6-10$, mean eGFR change per year was $-2.034 \mathrm{~mL} / \mathrm{min} / 1.73 \mathrm{~m}^{2}$. Between $10-15$ years, mean eGFR change was $0.454 \mathrm{~mL} / \mathrm{min} / 1.73 \mathrm{~m}^{2}$.

With longer follow-up beyond 1 year, an increasing proportion of patients develop stage III (moderate) to IV (severe) CKD (41.7\% at 10 years; Figure 2). Few patients remain at CKD stage I with long-term follow-up (39.7\% preoperative to $12.5 \%$ at 10 years). A greater proportion of hydronephrosis was identified over time, as $26(36.1 \%)$ patients had hydronephrosis at most recent follow-up, compared with $12(16.7 \%)$ of patients with preoperative hydronephrosis. Presence of hydronephrosis at 6-12 months follow-up was associated with decreased eGFR at 612 months $(\mathrm{p}<0.001), 1-5$ years $(\mathrm{p}=0.020), 10$ years $(\mathrm{p}=0.016)$, and 15 years $(\mathrm{p}=0.009)$.

\section{Urolithiasis and metabolic outcomes}


Ten (13.9\%) patients had documented electrolyte disorders (Table 2). A minority of patients $(\mathrm{N}=13 ; 18.1 \%)$ developed urinary stone disease. All stones required operative intervention through percutaneous nephrolithotomy, antegrade ureteroscopy, or transurethral cystolitholapaxy. Patients with longer duration of SNB ( $\geq 5$ years) were more likely to develop urolithiasis $(\mathrm{p}=0.013)$. Development of neobladder calculi was not associated with follow-up duration, sex, post-void residuals, or need for CIC. Development of upper urinary tract calculi was associated with decreased eGFR at most-recent follow-up (46.16 vs. $77.23 \mathrm{~mL} / \mathrm{min} / 1.73 \mathrm{~m}^{2}$; $\mathrm{p}=0.042)$ and presence of hydronephrosis at $6-12$ months $(80 \%$ vs. $31 \%$; $\mathrm{p}=0.047)$. There was no association between electrolyte disorders or bicarbonate use with upper or lower urinary tract calculi. There were no significant differences between groups in other functional, or metabolic complications over time (Table 2).

\section{Postoperative complications}

Fourteen anastomotic urinary leaks were documented; 9 (64.2\%) occurred within the early postoperative period ( $<30$ days) (Table S1). Anastomotic leaks were identified clinically (elevated surgical drain output) or on postoperative retrograde ureterogram. Details on management of postoperative leaks is described in Table S1. Of the 6 uretero-ileal anastomotic leaks, $5(83.3 \%)$ were on the left side.

Thirty-three occurrences of urinary obstruction were documented, including 17 ureteroileal stenoses in $14(19.4 \%)$ patients. Left uretero-ileal stenoses comprised the majority $(n=10$, $58.8 \%)$, followed by right $(\mathrm{n}=4,23.6 \%)$, and bilateral $(\mathrm{n}=3,17.6 \%)$. All patients who developed uretero-ileal stenosis underwent initial decompression with percutaneous nephrostomy tube to preserve renal function, with 10 requiring corrective surgical intervention at a later date (Table S1 for surgical details). The remaining patients were left with nephrostomy tubes or ureteral stents with regular changes. Fifteen occurrences of neobladder neck contracture were documented in $12(16.7 \%)$ patients, all of whom required some form of surgical intervention (e.g., urethral dilation, transurethral incision of bladder neck, etc). Three (4.2\%) patients with neobladder neck contracture required two or more interventions. One (1.4\%) case of urethral stricture occurred, requiring dilation.

Ten patients (13.9\%) developed urinary fistulae with or without bowel involvement, of which five required surgical correction. Anatomic and management details in Table S1. 


\section{Discussion}

Studer neobladder is an established form of continent urinary diversion and is a viable option for some patients who would prefer to optimize external appearance and avoid need for urostomy. In this study, we assessed functional, anatomic, and metabolic outcomes in patients who underwent SNB with longer-term follow-up.

\section{Urinary continence function}

A minority of patients in our series experienced DUI (16.7\%), with lower DUI rates reported by patients with longer follow-up (Table 2 and Figure 1). This is in contrast with long-term series of SNB, which have reported DUI rates of $25-61 \%,{ }^{15,17}$ that plateau at 12 months with stability and subsequent deterioration. ${ }^{17}$ Our cohort also showed lower NUI rates than other long-term series (44.4\% vs $75-79 \%)^{4,15,17}$ This may be partly explained by the younger average age of our sample compared with those evaluated in other long-term series (average age: 54.6 vs. 65-70 years), ${ }^{15,17}$ which is advantageous in terms of postoperative pelvic floor rehabilitation. Functional outcomes described in this series may also be explained by our pre-emptive approach to implementation of CIC. Indications for initiating CIC included elevated post-void residuals, deterioring renal function, increasing hydronephrosis, urinary retention, or recurrent urosepsis despite timed voiding. Patients also started CIC to prevent functional symptoms (i.e., once nightly to prevent NUI). Accordingly, our rates of CIC $(22.2 \%)$ are greater than reported in other series of SNB $(6-9.5 \%)^{10,15}$.

\section{Postoperative renal function}

Renal deterioration is common following SNB, as an increasing proportion of patients developed moderate to severe chronic kidney disease over time (Figure 2). As well, the prevalence of hydronephrosis identified 6-12 months postoperative (27.8\%) was increased compared to preoperative hydronephrosis $(16.7 \%)$. Lantz et al. ${ }^{18}$ similarly identified that $19.3 \%$ of patients had hydronephrosis at 12 months postoperatively. At most recent follow-up, the rate of hydronephrosis in our series increased to $36.1 \%$, though this was not associated with a decrease in mean eGFR. Higher rates of hydronephrosis with longer follow-up may be explained by refluxing ureteric anastomoses in some cases.

There have been few reports on long-term renal function in patients with orthotopic ileal neobladder. Jin et al. ${ }^{19}$ compared ileal conduit to ileal neobladders at 10 year follow-up and identified that $21 \%$ of patients with ileal neobladders had deterioration of renal function with minimal change in eGFR (difference in median eGFR: $-2 \mathrm{~mL} / \mathrm{min} / 1.73 \mathrm{~m}^{2}$ ). This finding is similar to the 10 year and 15 year eGFR change reported in this study $\left(+1.14 \mathrm{~mL} / \mathrm{min} / 1.73 \mathrm{~m}^{2}\right.$ and $-1.53 \mathrm{~mL} / \mathrm{min} / 1.73 \mathrm{~m}^{2}$, at 10 years and 15 years respectively), which may be due to selection bias for healthier patients with longer survival following SNB.

Moreover, Jin et al. identified that obstruction was the leading, and independent, risk factor for renal deterioration. ${ }^{19}$ This finding is supported by our data that indicates that 
hydronephrosis at 6-12 months follow-up was associated with renal function deterioration across 5 to 15 year follow-up periods. Eisenberg et al. ${ }^{20}$ similarly noted that postoperative hydronephrosis was predictive of renal function decrease, even after controlling for uretero-ileal anastomotic stenosis. Reflux nephropathy, therefore, may be a potential cause for renal deterioration; and early intervention (e.g. timed voiding, CIC, indwelling catheter) should be recommended for patients with SNB with overdistension and non-obstructive hydronephrosis in order to preserve renal function. Despite pre-emptive intervention with CIC, only a minority of patients will have preserved renal function (CKD stage I) at 10 years (12.5\%; Figure 2).

\section{Urolithiasis and metabolic outcomes}

Patients treated for metabolic acidosis with bicarbonate supplementation was similar between our series and others (4.2\% vs. 1.1-4.4\%). ${ }^{4}$ It is noteworthy that metabolic derangements occured early in the postoperative course as well as with longer term follow-up. Rates of vitamin B12 deficiency in this study were similar to other series (5.6\% vs. $4.8-13.6 \%)^{16,17}$ and only necessary in those with at least 5 years of diversion.

Urolithiasis (renal and ileal pouch) affected $28.9 \%$ of patients, primarily occurring after 5 years of follow-up. Rates of urolithiasis in our series was similar to that of other forms of intestinal urinary diversion $(2-43 \%) ;{ }^{18}$ however, long-term rates of urolithiasis in SNB have not been well documented. There were no risk factors associated with the development of neobladder calculi in this series. The association between upper urinary tract calculi following SNB and poorer renal function is unclear, but may be related to the presence of postoperative hydronephrosis secondary to obstruction or ureteral reflux..$^{21}$ Stone composition was not available for evaluation in this study, but stone formation following urinary diversion are commonly struvite due to bacterial colonization and diversion-related metabolic derangements. ${ }^{22,23}$

\section{Postoperative surgical intervention}

In the early postoperative period, our data indicates that anastomotic urinary leaks following SNB can often be managed without need for percutaneous drains or nephrostomy tubes. Rates of intervention for early postoperative urinary leaks have previously been reported to be approximately $5 \% .{ }^{24}$ In our series, all early postoperative urinary leaks were managed successfully with conservative endourologic means, as indicated in Table S1.

The most common indication for postoperative intervention in this series was for ureteroileal stenosis (19.4\%). All uretero-ileal stenoses were initially managed by percutaneous drainage, followed by endourologic techniques (e.g., antegrade ballon dilation), with open revision as a backup strategy (1.4\%; Table S1). Rates of balloon dilation of uretero-ileal stenosis in our sample were higher compared to those of similar studies (19.4\% vs. $2.7-11.1 \%)$, with similar rates of open revision (1.4\% vs. $0.9-2.4 \%){ }^{9,17}$ The higher rate of intervention for uretero- 
ileal stenosis may be attributed to pre-emptive treatment of uretero-ileal stenosis in asymptomatic patients to prevent long-term renal deterioration.

Neobladder outlet obstruction is relatively uncommon and may be attributed to local tumor recurrence infiltrating pelvic floor and neobladder neck, neobladder neck contracture, urethral stricture, or excessive angulation of the pouch relative to the urethra. ${ }^{25,26}$ The neobladder neck contracture rate in our series $(16.7 \%)$ was higher than other long-term series $(1-9 \%){ }^{25,27,28}$ Most neobladder neck contractures occured within the first year and all were treated endoscopically (Table S1). Recurrence of neobladder neck contracture $(n=5)$ generally occurred within 1 year of transurethal incision of bladder neck. Endoscopic management is recommended for neobladder neck contractures, with conversion to ileal conduit for recalcitrant cases. ${ }^{29}$ Although uncommon, incidence of neobladder fistulae may be higher than that of ileal conduit or Indiana pouch. ${ }^{30}$ In our series, 9 (12.5\%) fistulae were identified; none were associated with previous radiotherapy (Table S1). Identified causes of neobladder intestinal fistulae included recurrent malignancy, pelvic abscess, and diverticulitis (Table S1). Rates of neobladder intestinal fistulae seen in this series are similar to other long-term series (1.5-4.4\%). ${ }^{30,31}$ All cases of neobladder cutaneous fistulae (2.8\%) were successfully managed conservatively (Table S1).

\section{Limitations}

This study is limited by its retrospective design, and smaller sample size based at a single centre with strict inclusion criteria. Some patients were excluded due to surgery being performed in last 12 months, early ( $<12$ months) transfer of care back to community urologist, or lack of robust follow-up data sufficient for analysis. A small proportion of females who underwent SNB limited comparison of functional outcomes between sexes. Documentation of functional urinary outcomes may also have been under-reported. Use of validated questionnaires to record patient reported outcomes of urinary function was unfortunately not performed, nor were formal urodynamic evaluations or functional imaging generally conducted. Comprehensive long-term documentation of anatomical, functional, metabolic, and renal function outcomes should be considered through prospective data collection.

\section{Conclusions}

We assessed the functional, anatomical, and metabolic outcomes of patients who underwent Studer neobladder over two decades. Preoperative counselling on carefully selected patients should include long-term chronic renal function deterioration, metabolic derangements, and urinary continence issues including potential need for intermittent or long-term indwelling catheterization. Emphasis on conscientious avoidance of chronic bladder overdistention through fastidious timed-voinding and early initiation of intermittent catheterization may help to prevent renal deterioration, recurrent urosepsis, and some urinary dysfunction problems. Standardized follow-up protocols with monitoring of post-void residual, hydronephrosis, and metabolic and 
functional outcomes are essential for patients with Studer neobladder and may prevent long-term complications.

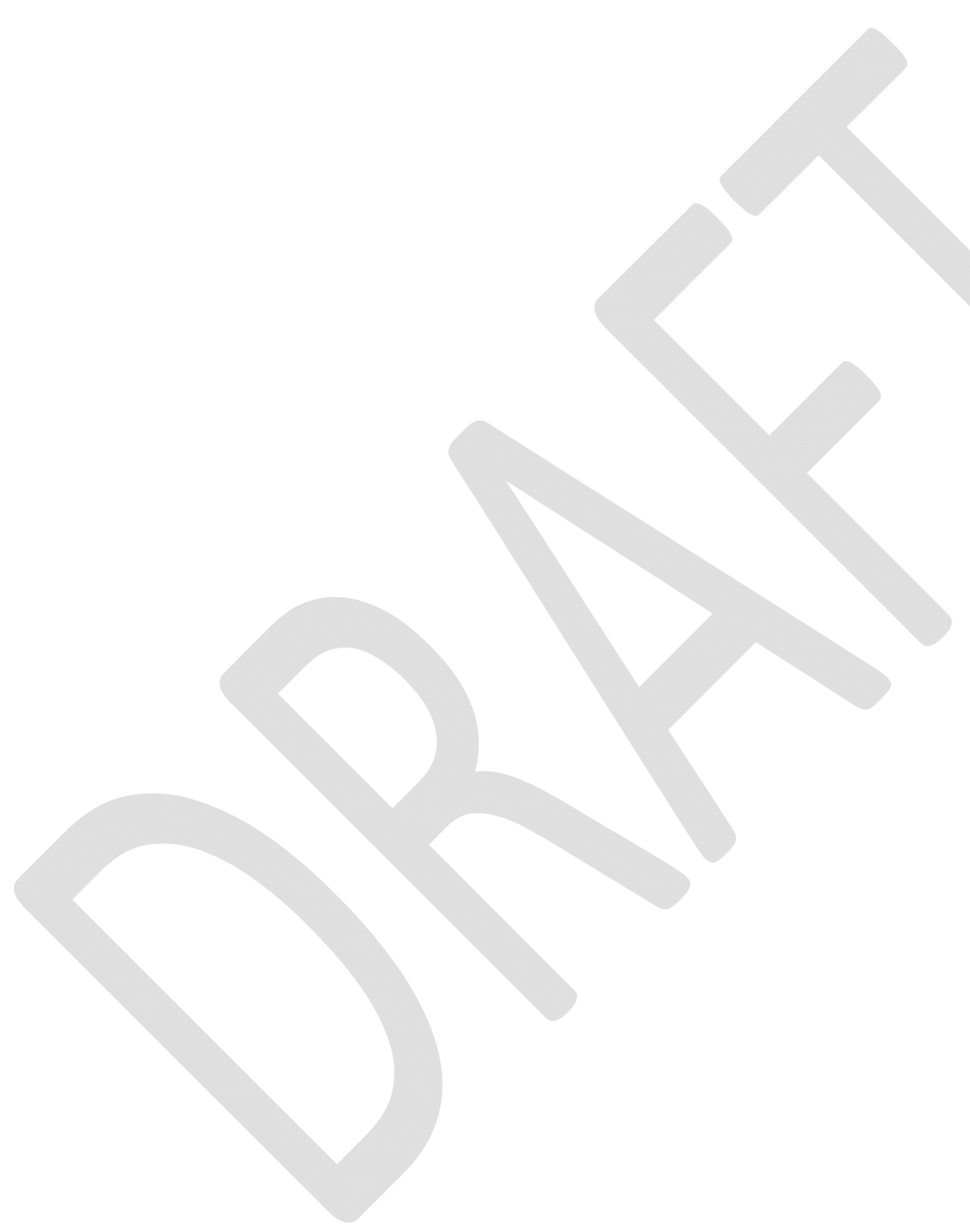




\section{References}

1. Chang DTS, Lawrentschuk N. Orthotopic neobladder reconstruction. Urol Ann. 2015;7(1):1-7. doi:10.4103/0974-7796.148553

2. Leveridge MJ, Jewett MAS. Which urinary diversion is best after radical cystectomy? The case for "incontinent" diversion. Can Urol Assoc J. 2008;2(4):410-411. http://www.ncbi.nlm.nih.gov/pubmed/18781208. Accessed April 8, 2019.

3. Ong K, Herdiman O, Johnson L, Lawrentschuk N. Orthotopic Bladder Substitution (Neobladder). J Wound, Ostomy Cont Nurs. 2013;40(1):73-82. doi:10.1097/WON.0b013e31827759ea

4. Hautmann RE, Volkmer BG, Schumacher MC, Gschwend JE, Studer UE. Long-term results of standard procedures in urology: the ileal neobladder. World J Urol. 2006;24(3):305-314. doi:10.1007/s00345-006-0105-z

5. Anderson CB, Cookson MS, Chang SS, Clark PE, Smith JA, Kaufman MR. Voiding Function in Women with Orthotopic Neobladder Urinary Diversion. J Urol. 2012;188(1):200-204. doi:10.1016/j.juro.2012.03.004

6. Hedgepeth RC, Gilbert SM, He C, Lee CT, Wood DP. Body Image and Bladder Cancer Specific Quality of Life in Patients With Ileal Conduit and Neobladder Urinary Diversions. Urology. 2010;76(3):671-675. doi:10.1016/J.UROLOGY.2010.01.087

7. Gburek BM, Lieber MM, Blute ML. Comparison of Studer Ileal Neobladder and Ileal Conduit Urinary Diversion with Respect to Perioperative Outcome and Late Complications. Vol 160.; 1998. https://www.auajournals.org/doi/pdf/10.1016/S00225347\%2801\%2962767-8. Accessed April 7, 2019.

8. Madersbacher S, Schmidt J, Eberle JM, et al. Long-Term Outcome of Ileal Conduit Diversion. J Urol. 2003;169(3):985-990. doi:10.1097/01.ju.0000051462.45388.14

9. Hautmann RE, de Petriconi RC, Volkmer BG. 25 Years of Experience With 1,000 Neobladders: Long-Term Complications. J Urol. 2011;185(6):2207-2212. doi:10.1016/j.juro.2011.02.006

10. Furrer MA, Roth B, Kiss B, et al. Patients with an Orthotopic Low Pressure Bladder Substitute Enjoy Long-Term Good Function. J Urol. 2016;196(4):1172-1180. doi:10.1016/J.JURO.2016.04.072

11. Thurairaja R, Burkhard FC, Studer UE. The orthotopic neobladder. BJU Int. 2008;102(9b):1307-1313. doi:10.1111/j.1464-410X.2008.07975.x

12. Chang SS, Bochner BH, Chou R, et al. American Society for Radiation Oncology ( ASTRO ) / Society of Urologic Oncology ( SUO ) BLADDER CANCER : AUA / ASCO / ASTRO / SUO American Urological Association ( AUA ) / American Society of Clinical Muscle - Invasive Oncology ( ASCO ) / American Societ. J Urol. 2017;198(March):1-42. doi:10.1016/j.juro.2017.04.086

13. Nayak AL, Cagiannos I, Lavallée L, et al. Urinary function following radical cystectomy and orthotopic neobladder urinary reconstruction. Can Urol Assoc J. 2018;12(6):181-186. doi:10.5489/cuaj.4877

14. Tanaka T, Kitamura H, Takahashi A, Masumori N, Itoh N, Tsukamoto T. Long-term Functional Outcome and Late Complications of Studer's Ileal Neobladder. Jpn J Clin Oncol. 2005;35(7):391-394. doi:10.1093/jjco/hyi112 
15. Ahmadi H, Skinner EC, Simma-Chiang V, et al. Urinary Functional Outcome Following Radical Cystoprostatectomy and Ileal Neobladder Reconstruction in Male Patients. $J$ Urol. 2013;189(5):1782-1788. doi:10.1016/j.juro.2012.11.078

16. Levey AS, Bosch JP, Lewis JB, Greene T, Rogers N, Roth D. A more accurate method to estimate glomerular filtration rate from serum creatinine: a new prediction equation. Modification of Diet in Renal Disease Study Group. Ann Intern Med. 1999;130(6):461470. http://www.ncbi.nlm.nih.gov/pubmed/10075613. Accessed June 17, 2019.

17. Studer UE, Burkhard FC, Schumacher M, et al. Twenty Years Experience With an Ileal Orthotopic Low Pressure Bladder Substitute-Lessons to be Learned. 2006. doi:10.1016/S0022-5347(06)00573-8

18. Lantz AG, Saltel ME, Cagiannos I. Renal and functional outcomes following cystectomy and neobladder reconstruction. Can Urol Assoc J. 2010;4(5):328-331. http://www.ncbi.nlm.nih.gov/pubmed/20944805. Accessed August 14, 2018.

19. Jin X-D, Roethlisberger S, Burkhard FC, Birkhaeuser F, Thoeny HC, Studer UE. Longterm Renal Function After Urinary Diversion by Ileal Conduit or Orthotopic Ileal Bladder Substitution. Eur Urol. 2012;61(3):491-497. doi:10.1016/J.EURURO.2011.09.004

20. Eisenberg MS, Thompson RH, Frank I, et al. Long-Term Renal Function Outcomes after Radical Cystectomy. J Urol. 2014;191:619-625. doi:10.1016/j.juro.2013.09.011

21. Hall MK, Hackler RH, Zampieri TA, Zampieri JB. Renal calculi in spinal cord-injured patient: Association with reflux, bladder stones, and foley catheter drainage. Urology. 1989;34(3):126-128. doi:10.1016/0090-4295(89)90245-8

22. Turk TMT, Koleski FC, Albala DM. Incidence of urolithiasis in cystectomy patients after intestinal conduit or continent urinary diversion. World J Urol. 1999;17(5):305-307. doi: $10.1007 / \mathrm{s} 003450050151$

23. Okhunov Z, Duty B, Smith AD, Okeke Z. Management of urolithiasis in patients after urinary diversions. BJU Int. 2011;108(3):330-336. doi:10.1111/j.1464410X.2011.10194.X

24. Skinner E, Daneshmand S. Results \&amp; Complications of Orthotopic Urinary Diversion | Campbell-Walsh.... In: Wein AJ, Kavoussi LR, Partin AW, Peters CA, eds. Campbell-Walsh Urology. Eleventh Edition. Philadelphia: Elsevier, Inc.; 2012. https://expertconsult.inkling.com/read/wein-campbell-walsh-urology-11th/chapter99/results-and-complications-of\#fec266e1c70243b6bd4c8931cf30efef. Accessed July 23, 2019.

25. Hautmann RE, De Petriconi RC, Volkmer BG. 25 Years of Experience With 1,000 Neobladders: Long-Term Complications. J Urol. 2011;185:2207-2212. doi:10.1016/j.juro.2011.02.006

26. Park JM, Montie JE. Mechanisms of incontinence and retention after orthotopic neobladder diversion. Urology. 1998;51(4):601-609. doi:10.1016/S0090-4295(97)006973

27. Kulkarni JN, Pramesh CS, Rathi S, Pantvaidya GH. Long-term results of orthotopic neobladder reconstruction after radical cystectomy. BJU Int. 2003;91(6):485-488. doi:10.1046/j.1464-410X.2003.04131.x

28. Patel SG, Cookson MS, Clark PE, Smith JA, Chang SS. Neovesical-urethral anastomotic stricture after orthotopic urinary diversion: Presentation and management. BJU Int. 
2008;101(2):219-222. doi:10.1111/j.1464-410X.2007.07237.x

29. Pariser JJ, Saltzman GB, Bales GT, Steinberg GD, Smith ND. Outcomes of the

Endoscopic Treatment of Bladder Neck Contractures in the Orthotopic Neobladder.

Urology. 2015;86(3):613-617. doi:10.1016/j.urology.2015.06.020

30. Msezane L, Reynolds WS, Mhapsekar R, Gerber G, Steinberg G. Open Surgical Repair of Ureteral Strictures and Fistulas Following Radical Cystectomy and Urinary Diversion. J Urol. 2008;179(4):1428-1431. doi:10.1016/j.juro.2007.11.083

31. Studer UE, Burkhard FC, Schumacher M, et al. Twenty Years Experience With an Ileal Orthotopic Low Pressure Bladder Substitute-Lessons to be Learned. J Urol. 2006;176(1):161-166. doi:10.1016/S0022-5347(06)00573-8 


\section{Figures and Tables}

Fig. 1. Most recent functional voiding outcomes by duration of followup. Patients with longer followup duration report lower rates of daytime urinary incontinence (DUI) and NUI (nighttime urinary incontinence than those with less than 5 years of followup. This may be explained by higher clean intermittent catthetization (CIC) rates in patients with longer followup as a part of bladder emptying protocols. Post-void residual rates remain relatively stable over longer-term followup.

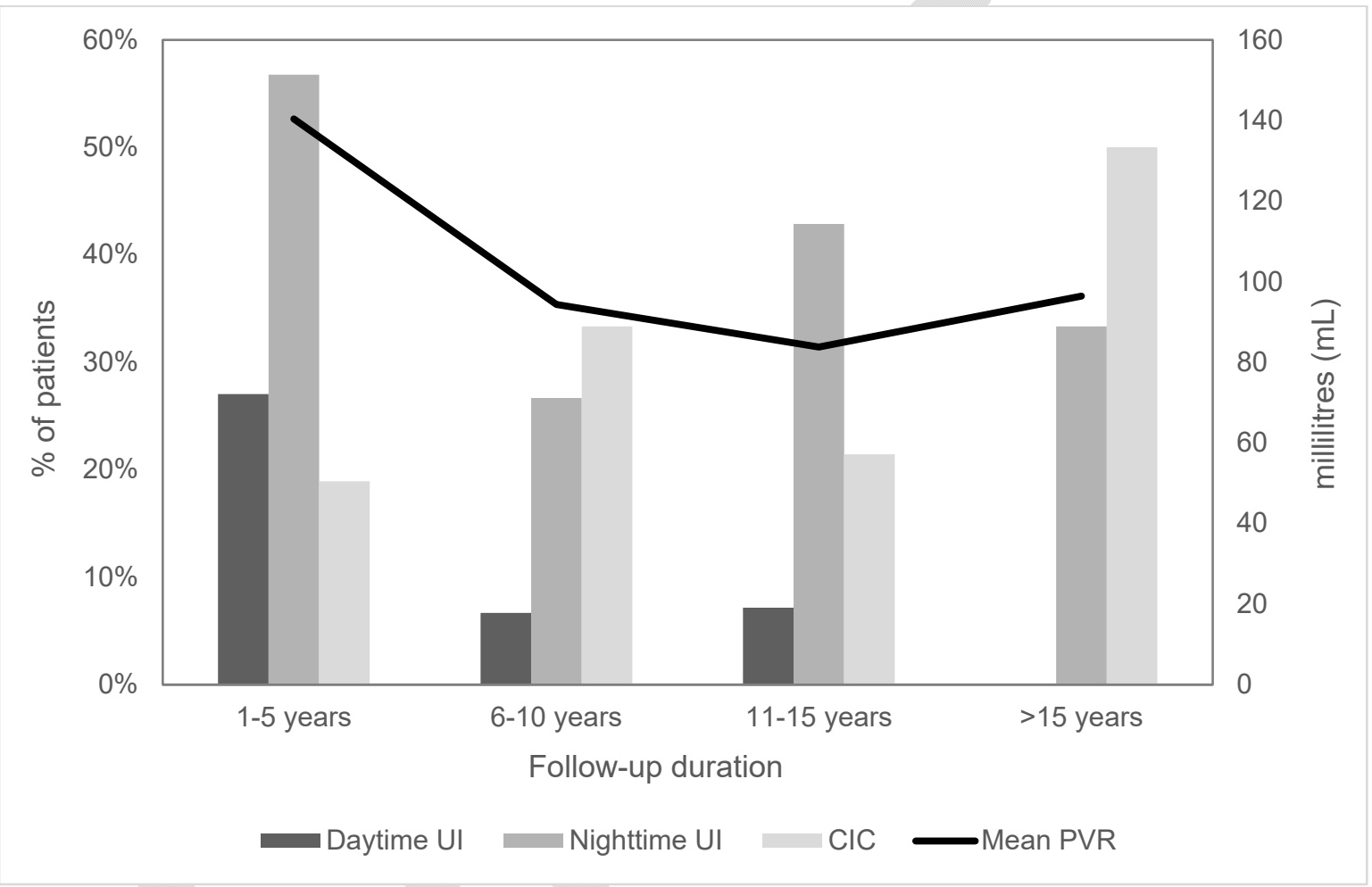


Fig. 2. Chronic kidney disease (CKD) stage over time. Increasing proportion of patients develop stage IIIIV CKD with longer followup.

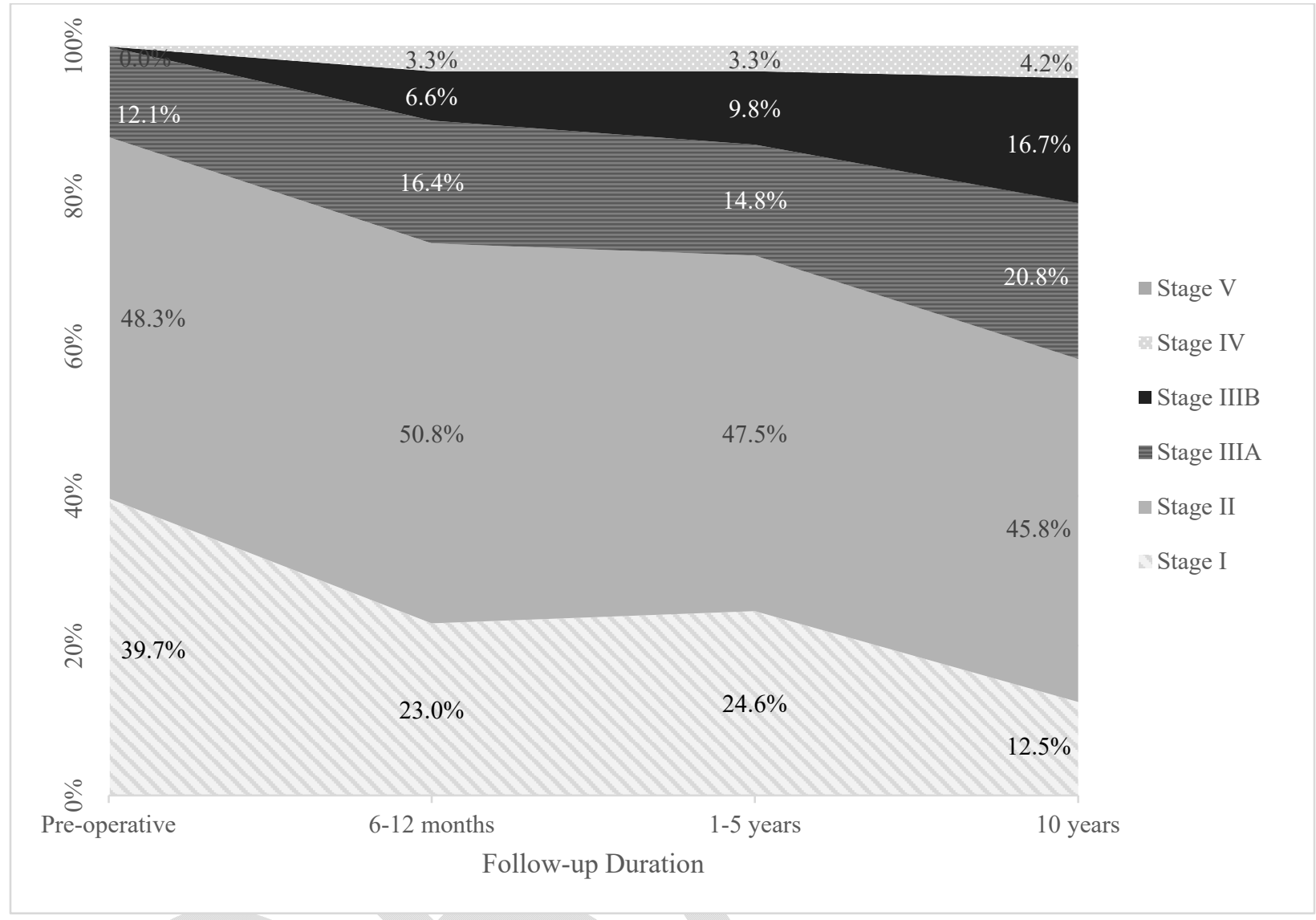




\begin{tabular}{|c|c|c|c|c|c|c|c|}
\hline Patient demographics & $\begin{array}{c}\text { All } \\
(n=72)\end{array}$ & $\begin{array}{c}<5 \text { years } \\
(n=34)\end{array}$ & $\begin{array}{c}\geq 5 \text { years } \\
(n=38)\end{array}$ & $\mathbf{p}$ & $\begin{array}{c}\text { Male } \\
(n=61)\end{array}$ & $\begin{array}{c}\text { Female } \\
(n=11)\end{array}$ & $\mathbf{p}$ \\
\hline Age at surgery, mean years (SD) & $54.6(8.6)$ & $56.6(7.2)$ & $53.29(9.5)$ & 0.122 & $\begin{array}{l}55.08 \\
(7.6)\end{array}$ & $53.45(13.2)$ & 0.994 \\
\hline Female sex, n (\%) & $\begin{array}{c}11 \\
(15.3 \%)\end{array}$ & $6(18 \%)$ & $5(13 \%)$ & 0.746 & - & - & - \\
\hline CCI, median (IQR) & $4(2-6)$ & $4(2-6)$ & $4(1-7)$ & 0.789 & $4(2-6)$ & $4(1-7)$ & 0.785 \\
\hline Prior pelvic radiotherapy, $\mathrm{n}(\%)$ & 0 & 0 & 0 & - & 0 & 0 & - \\
\hline Chemotherapy, ${ }^{*} \mathrm{n}(\%)$ & $\begin{array}{c}27 \\
(37.5 \%)\end{array}$ & $26(76.5 \%)$ & $11(28.9 \%)$ & 0.150 & $\begin{array}{c}23 \\
(37.7 \%)\end{array}$ & $4(36.4 \%)$ & 0.999 \\
\hline $\begin{array}{l}\text { Followup duration, median years } \\
\text { (IQR) }\end{array}$ & $5(0-13)$ & $2(0-4)$ & $11(5-16)$ & $<0.001$ & $6(1-11)$ & $3(0-7.5)$ & 0.374 \\
\hline \multicolumn{8}{|l|}{ Postoperative complications } \\
\hline Clavien-Dindo classification $^{* *}$ & 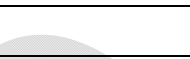 & 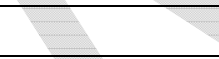 & 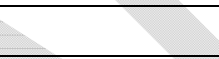 & & & & \\
\hline 0 & $\begin{array}{c}29 \\
(40.3 \%)\end{array}$ & $12(35.3 \%)$ & $17(44.7 \%)$ & 0.223 & $25(49 \%)$ & $4(36.4 \%)$ & 0.172 \\
\hline $\mathrm{I}$ & $\begin{array}{c}21 \\
(29.2 \%)\end{array}$ & $10(29.4 \%)$ & $11(28.9 \%)$ & & $\begin{array}{c}19 \\
(37.2 \%)\end{array}$ & $2(22.2 \%)$ & \\
\hline II & $6(8.3 \%)$ & $4(11.8 \%)$ & $2(5.3 \%)$ & & $5(9.8 \%)$ & $1(9.1 \%)$ & \\
\hline III & $3(4.2 \%)$ & $3(8.8 \%)$ & 0 & & $2(3.9 \%)$ & $1(9.1 \%)$ & \\
\hline IV & $1(1.4 \%)$ & $1(2.9 \%)$ & 0 & & 0 & $1(9.1 \%)$ & \\
\hline Missing & $\begin{array}{c}12 \\
(16.7 \%) \\
\end{array}$ & $4(11.8 \%)$ & $9(21.1 \%)$ & & $\begin{array}{c}10 \\
(19.6 \%) \\
\end{array}$ & $2(18.2 \%)$ & \\
\hline \multicolumn{8}{|l|}{ Readmission within 90 days } \\
\hline Yes & $\begin{array}{c}15 \\
(20.8 \%)\end{array}$ & $8(23.5 \%)$ & $7(18.4 \%)$ & 0.773 & $8(14.2 \%)$ & $2(13.3 \%)$ & 0.999 \\
\hline \multicolumn{8}{|l|}{ Tumor characteristics } \\
\hline Pathological stage & No. $(\%)$ & & & & & & \\
\hline T0 & $4(5.6 \%)$ & $1(2.9 \%)$ & $3(7.9 \%)$ & 0.109 & $4(2.0 \%)$ & 0 & 0.625 \\
\hline
\end{tabular}


Outcomes with Studer neobladders

\begin{tabular}{|c|c|c|c|c|c|c|c|}
\hline $\mathrm{Ta}$ & $1(1.4 \%)$ & $1(2.9 \%)$ & 0 & & $1(1.6 \%)$ & 0 & \\
\hline Tis & $\begin{array}{c}12 \\
(16.7 \%) \\
\end{array}$ & $3(8.8 \%)$ & $9(23.7 \%)$ & & $\begin{array}{c}11 \\
(18.0 \%) \\
\end{array}$ & $1(9.1 \%)$ & \\
\hline T1 & $9(12.5 \%)$ & $2(5.9 \%)$ & $7(18.4 \%)$ & & $9(14.8 \%)$ & 0 & \\
\hline $\mathrm{T} 2$ & $\begin{array}{c}21 \\
(29.2 \%)\end{array}$ & $13(38.2 \%)$ & $8(21.1 \%)$ & & $\begin{array}{c}16 \\
(26.2 \%)\end{array}$ & $5(45.5 \%)$ & \\
\hline T3 & $\begin{array}{c}17 \\
(23.6 \%)\end{array}$ & $10(29.4 \%)$ & $7(18.4 \%)$ & & $\begin{array}{c}13 \\
(21.3 \%)\end{array}$ & $4(36.4 \%)$ & \\
\hline $\mathrm{T} 4$ & $6(8.3 \%)$ & $4(11.8 \%)$ & $2(5.3 \%)$ & & $5(8.2 \%)$ & $1(9.1 \%)$ & \\
\hline Missing & $2(2.8 \%)$ & 0 & $2(5.3 \%)$ & 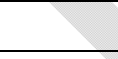 & $2(3.3 \%)$ & 0 & \\
\hline Histopathological type & & & 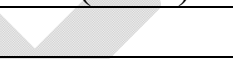 & & & & \\
\hline Urothelial cell carcinoma & $\begin{array}{c}60 \\
(83.3 \%) \\
\end{array}$ & $30(88.2 \%)$ & $30(78.9 \%)$ & 0.615 & $\begin{array}{c}54 \\
(88.5 \%) \\
\end{array}$ & $6(54.5 \%)$ & 0.007 \\
\hline Squamous cell carcinoma & $4(5.6 \%)$ & $1(2.9 \%)$ & $3(7.9 \%)$ & & $1(1.6 \%)$ & $3(27.3 \%)$ & \\
\hline Adenocarcinoma & $1(1.4 \%)$ & 0 & $1(2.6 \%)$ & & $1(1.6 \%)$ & 0 & \\
\hline Missing & $7(9.7 \%)$ & $3(8.8 \%)$ & $4(10.5 \%)$ & & $5(8.2 \%)$ & $2(18.2 \%)$ & \\
\hline
\end{tabular}

"Neoadjuvant or adjuvant chemotherapy. ${ }^{* *}$ Complications within 90 days. Data collected for patients with $\geq 1$-year followup. $<1$-year followup included one Clavien V and three Clavien IV complications. CCI: Charlson comorbidity index; IQRL interquartile range; SD: standard deviation. 
Table 2. Functional, antomical, and metabolic outcomes following Studer neobladder urinary diversion by followup duration ( $<5$ years vs. $\geq 5$ years) and patient gender

\begin{tabular}{|c|c|c|c|c|c|c|c|}
\hline & & \multicolumn{2}{|c|}{ Followup duration } & $\mathbf{p}$ & \multicolumn{2}{|c|}{ Gender } & \multirow[t]{2}{*}{$\mathbf{p}$} \\
\hline & $\begin{array}{l}\text { Total } \\
(\mathrm{n}=72)\end{array}$ & $\begin{array}{c}<5 \text { years } \\
(\mathrm{n}=34)\end{array}$ & $\begin{array}{c}\geq 5 \text { years } \\
(n=38)\end{array}$ & & $\begin{array}{c}\text { Male } \\
(\mathrm{n}=61)\end{array}$ & $\begin{array}{l}\text { Female } \\
(n=11)\end{array}$ & \\
\hline \multicolumn{8}{|l|}{ Need for catheterization } \\
\hline $\begin{array}{l}\text { Permanent indwelling } \\
\text { catheter, } \mathrm{n}(\%)\end{array}$ & $3(4.3 \%)$ & $1(2.9 \%)$ & $2(5.3 \%)$ & 0.999 & $3(9.8 \%)$ & 0 & 0.999 \\
\hline $\begin{array}{l}\text { Clean intermittent } \\
\text { catheterization, } \mathrm{n}(\%)\end{array}$ & $16(22.2 \%)$ & $\begin{array}{c}6 \\
(17.6 \%)\end{array}$ & $\begin{array}{c}10 \\
(26.3 \%) \\
\end{array}$ & 0.276 & $\begin{array}{c}11 \\
(18.0 \%)\end{array}$ & $5(45.5 \%)$ & 0.059 \\
\hline \multicolumn{8}{|c|}{ Lower urinary tract symptoms } \\
\hline Frequency, n (\%) & $6(8.3 \%)$ & $\begin{array}{c}4 \\
(11.8 \%)\end{array}$ & $2(5.3 \%)$ & 0.412 & $6(9.8 \%)$ & 0 & 0.581 \\
\hline Nocturia, n (\%) & $9(12.5 \%)$ & $\begin{array}{c}4 \\
(11.8 \%)\end{array}$ & $5(13.2 \%)$ & 0.999 & $\begin{array}{c}8 \\
(13.1 \%)\end{array}$ & $1(9.1 \%)$ & 0.999 \\
\hline \multicolumn{8}{|l|}{ Urinary incontinence } \\
\hline $\begin{array}{l}\text { Daytime urinary } \\
\text { incontinence, }{ }^{*} \text { n (\%) }\end{array}$ & $12(16.7 \%)$ & $\begin{array}{c}9 \\
(26.5 \%)\end{array}$ & $3(7.9 \%)$ & 0.056 & $\begin{array}{c}8 \\
(13.1 \%)\end{array}$ & $4(36.3 \%)$ & 0.078 \\
\hline $\begin{array}{l}\text { Nighttime urinary } \\
\text { incontinence, } \mathrm{n}(\%)\end{array}$ & $32(44.4 \%)$ & $\begin{array}{c}18 \\
(52.9 \%) \\
\end{array}$ & $\begin{array}{c}14 \\
(36.8 \%) \\
\end{array}$ & 0.235 & $\begin{array}{c}26 \\
(42.6 \%)\end{array}$ & $6(54.5 \%)$ & 0.522 \\
\hline \multicolumn{8}{|l|}{ Post-void residual } \\
\hline $\begin{array}{l}\text { Post-void residual, mean, } \\
\text { mL (SD) }\end{array}$ & $\begin{array}{c}110.9 \\
(180.7)\end{array}$ & $\begin{array}{l}125.94 \\
(207.0)\end{array}$ & $\begin{array}{l}101.59 \\
(165.5)\end{array}$ & 0.886 & $\begin{array}{l}254.6 \\
(295.3)\end{array}$ & $\begin{array}{l}93.81 \\
(159.1)\end{array}$ & 0.242 \\
\hline \multicolumn{8}{|l|}{ Infection } \\
\hline Recurrent UTI, n (\%) & $25(34.7 \%)$ & $\begin{array}{c}10 \\
(29.4 \%)\end{array}$ & $\begin{array}{c}15 \\
(39.5 \%)\end{array}$ & 0.460 & $\begin{array}{c}19 \\
(31.1 \%)\end{array}$ & $6(54.5 \%)$ & 0.173 \\
\hline \multicolumn{8}{|l|}{ Urolithiasis } \\
\hline Any stones, ${ }^{* *} \mathrm{n}(\%)$ & $13(18.1 \%)$ & $\begin{array}{c}2 \\
(5.9 \%)\end{array}$ & $\begin{array}{c}11 \\
(28.9 \%)\end{array}$ & 0.013 & $\begin{array}{c}12 \\
(19.7 \%)\end{array}$ & $\begin{array}{c}1 \\
(9.1 \%)\end{array}$ & 0.676 \\
\hline $\begin{array}{l}\text { Upper urinary tract, } \mathrm{n} \\
(\%)\end{array}$ & $8(11.1 \%)$ & $\begin{array}{c}1 \\
(2.9 \%)\end{array}$ & $7(18.4 \%)$ & 0.059 & $\begin{array}{c}7 \\
(11.4 \%)\end{array}$ & $\begin{array}{c}1 \\
(9.1 \%)\end{array}$ & 0.999 \\
\hline Neobladder, n (\%) & $6(8.3 \%)$ & $\begin{array}{c}1 \\
(2.9 \%)\end{array}$ & $5(13.2 \%)$ & 0.203 & $6(9.8 \%)$ & 0 & 0.581 \\
\hline
\end{tabular}




\begin{tabular}{|c|c|c|c|c|c|c|c|}
\hline \multicolumn{8}{|l|}{ Metabolic disorders } \\
\hline $\begin{array}{l}\text { Electrolyte disorder, } \mathrm{n} \\
(\%)\end{array}$ & $10(13.9 \%)$ & $\begin{array}{c}6 \\
(17.6 \%)\end{array}$ & $4(10.5 \%)$ & 0.504 & $\begin{array}{c}9 \\
(14.8 \%)\end{array}$ & $\begin{array}{c}1 \\
(9.1 \%)\end{array}$ & 0.999 \\
\hline Bicarbonate use, ${ }^{* * *} \mathrm{n}(\%)$ & $\begin{array}{c}3 \\
(4.2 \%)\end{array}$ & $\begin{array}{c}1 \\
(2.9 \%)\end{array}$ & $\begin{array}{c}2 \\
(5.3 \%)\end{array}$ & 0.999 & $\begin{array}{c}3 \\
(4.9 \%)\end{array}$ & 0 & 0.999 \\
\hline $\begin{array}{l}\text { Vitamin B12 deficiency, } \\
\mathrm{n}(\%)\end{array}$ & $\begin{array}{c}4 \\
(5.6 \%)\end{array}$ & 0 & $4(10.5 \%)$ & 0.116 & $\begin{array}{c}4 \\
(6.6 \%)\end{array}$ & 0 & 0.999 \\
\hline
\end{tabular}

${ }^{*}$ Defined as requiring use of a daily pad for urinary incontinence. ${ }^{* *}$ One patient developed both upper urinary tract calculi and neobladder calculi requiring intervention. ${ }^{* * *}$ Oral bicarbonate therapy due to hyperchloremic metabolic acidosis secondary to ileal urinary diversion. 